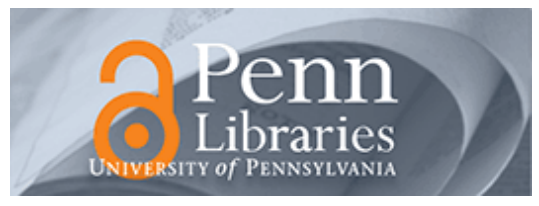

University of Pennsylvania

ScholarlyCommons

Marketing Papers

Wharton Faculty Research

December 1982

\title{
Strategies for implementing change: an experiential approach
}

\author{
J. Scott Armstrong \\ University of Pennsylvania, armstrong@wharton.upenn.edu
}

Follow this and additional works at: https://repository.upenn.edu/marketing_papers

\section{Recommended Citation}

Armstrong, J. S. (1982). Strategies for implementing change: an experiential approach. Retrieved from https://repository.upenn.edu/marketing_papers/33

Copyright Sage Publications. Postprint version. Published in Group \& Organization Studies, Volume 7, Number 4, December 1982, pages 457-475. The author has asserted his/her right to include this material in ScholarlyCommons@Penn.

This paper is posted at ScholarlyCommons. https://repository.upenn.edu/marketing_papers/33

For more information, please contact repository@pobox.upenn.edu. 


\title{
Strategies for implementing change: an experiential approach
}

\author{
Abstract \\ An attitude survey and a role-playing case were used to identify the typical approaches people use to \\ implement important changes in organizations. This typical strategy, suggested or used by over $90 \%$ of \\ the subjects, was not successful in producing change in any of the fourteen role-playing trials. However, \\ with ten minutes of instruction in the "Delta Technique," $86 \%$ of the subjects were successful in \\ introducing change in another fourteen role-playing trials. The "Delta Technique" consists of simple rules \\ drawn from half a century of research.

\section{Comments} \\ Copyright Sage Publications. Postprint version. Published in Group \& Organization Studies, Volume 7, \\ Number 4, December 1982, pages 457-475. The author has asserted his/her right to include this material \\ in ScholarlyCommons@Penn.
}


Published in Group \& Organization Studies, Vol. 7, No. 4 (1982) 457-475.

\section{Strategies for Implementing Change: An Experiential Approach}

\section{J. Scott Armstrong}

An attitude survey and a role-playing case were used to identify the typical approaches people use to implement important changes in organizations. This typical strategy, suggested or used by over $90 \%$ of the subjects, was not successful in producing change in any of the fourteen role-playing trials. However, with ten minutes of instruction in the "Delta Technique," $86 \%$ of the subjects were successful in introducing change in another fourteen role-playing trials. The "Delta Technique" consists of simple rules drawn from half a century of research.

Partial funding of this project was provided by IMEDE, Lausanne, Switzerland

Previous research has provided useful guidelines on how to implement change successfully. Despite the published research, popularized restatements, and education courses that provide guidelines for change, managers typically use intuitive strategies to introduce change. These intuitive strategies are seldom effective in situations calling for important behavioral changes.

It appears that one more study on how to implement change would have little effect on the situation. This is consistent with research in social psychology such as that by Nisbett and Borgida (1975). They found that people were unwilling to generalize from research on others. For example, evidence of what worked for over 95 of 100 people was seldom used by individuals to change their own behavior. But, they were often willing to generalize from their own experience to say how they would act in the future and to predict how others would act.

Instead of providing one more study, then, this article focuses on an experiential approach to strategies for change. It begins with a short exercise for the reader. (This approach could be easily extended to a classroom situation). Following this, two strategies are discussed. The first is the one most commonly used; the second, called the Delta Technique, is developed from a substantial body of published research.

One aspect of the experiential approach is that you are asked to solve a problem before you are given $n$ technique for solving it. Thus, I will ask you to solve the COMPU-HEART case before I present the Delta Technique.

Another aspect of the experiential approach relates to your orientation as a reader. It is suggested that the Delta Technique is a proven method - for others. But it may differ from your current approach to change. How would you react to this information? There are other possibilities, but check the item closest to your expected reaction:

(A) I will disagree with the Delta Technique. This article will not provide enough information to convince me.

(B) I will decide that it was really a communication problem - that I already use the Delta Technique but have different words for it.

(C) I will feel that I had read an exciting article and agree that the Delta Technique is excellent.

(D) I will take action by experimenting with the Delta Technique. 
Alternative D, to experiment, creates stress. Yet D has the most value to you and your organization. Those selecting A will feel bad, Bs will feel O.K., and Cs will feel good: But D provides an opportunity to benefit from this article. (If you would like to compare your responses with others, a sample of MBAs from two organizational behavior courses at Wharton answered this question before reading this article. Of the 23 respondents, $65 \%$ selected alternative D (to experiment), 18\% selected A (to disagree), 13\% selected C (exciting article), and one person selected B (communication problem).

To examine your own approach to change, consider the COMPU-HEART Case.

\section{THE COMPU-HEART CASE}

Assume you are on the administrative staff at Rosemont Hospital. What strategy would you use to implement change in this problem?

To provide space for its outpatient facilities, Rosemont Hospital had examined its inpatient program. When considering the whole system they concluded that there were clear-cut benefits in reducing the space allotted to patients with heart problems. In fact, they were excited about a program called COMPU-HEART, which provides home treatment for heart patients. This could be done by paramedics who visit the patient, perform some simple tests, and ask questions of the patient. The paramedics then call a time-sharing computer system that suggests what steps should be taken (e.g., "do nothing," "send patient to hospital," "contact personal physician," "eliminate drug $\mathrm{X}$," and so on). This program was developed by modeling the decisions used by a committee composed of ten of the best heart specialists in the world. The computer is already used by Rosemont for other purposes, so the startup costs would not be large.

An experimental study run at a hospital in Los Angeles found that use of COMPU-HEART resulted in:
(1) fewer fatalities,
(2) faster recovery rate for patients,
(3) more satisfaction among patients, and
(4) much lower costs.

However, you realize that when previous suggestions of a similar nature had been made, the doctors were skeptical. So, even though the doctors are currently overworked and this proposal would save time for them, you expect them to resist this change. The doctors prefer to have the patients in the hospital where they can see them and talk with them. They do not trust paramedics or computers to handle their patients for them.

You have scheduled a meeting with the doctors' decision making committee. You would like to convince them to accept the COMPU-HEART program.

Before going on, you will find it helpful to take at least ten minutes to write your procedure for introducing change in the COMPU-HEART Case.

\section{RESULTS}

I presented the above written description of the COMPU-HEART case to a class of seventeen seniors in a Wharton course in September 1981. These students, who had all taken courses in organizational behavior, were given fifteen minutes to write a strategy that they would use to convince the doctors to adopt the COMPU-HEART system. They were asked to provide enough detail so that someone else could follow their strategy. They were also told that a strategy would be selected from someone in the group to use in a role-playing trial. 
I coded the strategies. (Copies of these strategies can be obtained from the author. However, this task can be easily replicated.) Two months after the initial administration, I returned the strategies to the participants and asked them to code them. Sixteen of their replies were capable of being coded. Both codings produced nearly identical results, as shown in Table 1. Only one of the participants used the Delta Technique.

Table 1. Coding of Strategy

Coded by:

\begin{tabular}{lcc}
\hline Approach & Armstrong & Subjects \\
\hline Rational & 11 & 12 \\
Mixed & 4 & 3 \\
Delta & 1 & 1 \\
\hline
\end{tabular}

I also presented the COMPU-HEART Case as a role-playing exercise. It was administered as a teaching vehicle on fifteen occasions from May 1978 to June 1980 in a two-day seminar on health care marketing. Most participants were high-level executives in hospitals and other health care institutions; a few came from companies that supply goods to health care institutions.

Two volunteers from each group acted as staff members. An additional two volunteers played the roles of the doctors. The role players were given about ten minutes to prepare, using only the information provided above. The role playing itself required about ten minutes to reach an outcome. In fourteen of the fifteen trials, the "staff" used primarily rational arguments. This strategy was never successful in gaining agreement to change by the doctors. The only staff group that was successful in introducing change did not use the rational approach; instead, their strategy was similar to the Delta Technique.

Two additional members in each group had volunteered to act as staff members in case the first staff group was unsuccessful. These staff members were given instructions for the Delta Technique (see Appendix) and were asked to follow them when meeting with the doctors. This second role play took place prior to discussion of the first role play. Staff members in two of the fourteen groups had difficulty applying the Delta strategy and met with no success. All other groups achieved success by gaining agreement in principle for an experiment and by scheduling another meeting. Despite the short time available for this role play (generally less than ten minutes), most groups achieved success as judged by the instructor and the class. This increase in effectiveness from $7 \%$ success without training in Delta, to $86 \%$ with training, was dramatic and statistically significant $(\mathrm{p}<.001$ using X2 test). Over the past ten years, I have used two other versions of this case; one dealing with a change in a hiring policy and the other dealing with the adoption of a new forecasting method. Often the role players were given a few days to prepare. The role playing has been conducted with undergraduates and MBA students as well as executives. The results were similar to those in the COMPU-HEART Case.

Delta also worked in real life. COMPU-HEART is a disguised version of a study published by Marrow and French (1945). During World War II, the Harwood Manufacturing Company, a manufacturer of pajamas, was having difficulty in hiring workers. "Older women" were available, but management believed that they were not good workers. A number of empirical studies indicated that, in fact, they were excellent workers.

Harwood used an approach similar to Delta. Top management was in control of the change process and they conducted an experiment to test their beliefs. This experiment provided disconfirming evidence for their current practice and they changed: They decided to hire older women. But before making a final decision, they used the Delta Technique with the other key stakeholders in their organization.

From a research viewpoint, there were limitations. Both the survey and the role playing were administered by me, and I have become an advocate of the Delta Technique. Furthermore, the judgments of the outcomes were made by me. On the positive side, the differences in outcomes between the rational approach and the Delta Technique were so large that there was little need for precise measurement. Most important, however, is the fact that this result can be easily replicated by the reader, using the information provided here. 
Below, I discuss the rational approach and why it fails to produce important behavior change. Then I discuss the Delta Technique in more detail.

\section{THE RATIONAL APPROACH}

Mosteller (1981) provides a brief history on the rational approach to an important problem. At one time, scurvy would contribute to the deaths of perhaps half of the sailors on long voyages. In 1601, an Englishman, James Lancaster, conducted an experiment and found that lemons were effective in preventing scurvy. This was the first in a series of rational steps. But the British Navy did not adopt the use of lemons. About 150 years later, James Lind conducted an experiment that showed citrus fruits to be effective in preventing scurvy. The British Navy did not adopt citrus fruits until 1795, nearly 50 years later. The British Board of Trade followed 70 years later, in 1865 . In other words, given rational and convincing evidence on the life-saving capability of citrus fruits, it required 264 years for the findings to be adopted by the British merchant marine.

Consider the rational approach to current problems. What if I presented evidence to managers of large corporations showing that personal interviewing of potential management employees is a poor investment because it is expensive, reduces the quality of the people hired, and introduces prejudice into hiring? (I believe research supports all of these statements.) How would the managers involved react to such information?

To examine the rational approach, Batson (1975) asked members of a church youth group to indicate on a questionnaire how strongly they believed that Jesus Christ was God. They were then told that documents had recently been discovered by archaeologists. These documents were said to be correspondence that took place among the apostles after Christ died and the theme was similar to a Watergate cover up:

"Now that Christ has died, people will realize that he is not God, so all is lost."

"Perhaps not. People want to believe that Christ is God, so maybe we can continue with this deception."

The members of this youth group were told that The New York Times, under pressure from the World Council of Churches, was withholding the story. The group was led to think that the reactions of various people were being studied to see what would happen if and when The New York Times released the story. After learning about the documents, the youth group members completed a second questionnaire that again asked how strongly they believed that Christ was God.

Here is what happened. Nonbelievers lessened their belief that Christ was God, but those with a strong belief that Christ was God reported a strengthening of their belief. This strengthening occurred only for those believers who thought the information was authentic.

How can we explain Batson's results? Certainly they are not based on "common sense." I presented a description of this study, on a self-administered questionnaire, to sixteen Wharton School seniors, none of whom had previously heard of the Batson study. None of the sixteen respondents was able to predict the complete results of Batson's studies. Furthermore, only three of the sixteen were correct in their prediction of the direction of attitude change for the group of primary concern, the youth group members who believed that Christ was God and who also believed the information to be authentic.

Similar results were obtained from a group of executives attending a strategic planning course at INSEAD, in Fontainebleau, France, in April 1981. Only three of fourteen respondents correctly predicted the increased belief among the believers who thought they had received authentic evidence. Batson had designed his study as a further test of the theory of cognitive dissonance. This theory is widely known and is routinely included in programs on management education. Another way to view it is in terms of balance theory (see Brown, 1965, for a description). Balance theory can be used to examine the key elements of this study from the viewpoint of the changes, that is, the youth group member who believed Christ is God. These elements are the youth group member, the researchers, and the message about Christ. They are illustrated in Figure 1, where the signs represent evaluations. Thus, the minus 
sign indicates that the youth group member does not like the message that "Christ is not God." According to balance theory, when you multiply the signs, the product should be positive. If not, the situation creates dissonance. To obtain a positive product in Figure 1, a youth could change the "?" to a "-" by deciding that the researchers are not competent or credible. Such a change creates balance, thus requiring no further change. (This is alternative A in the introduction to this article).

An alternative solution is for the youth group member to decide he or she heard things incorrectly; that is, the link between the researchers and the message was really negative. Then the youth group member could be favorable toward the researchers $(+$ ). (This could lead to either strategy B or C described in the experiential introduction.) Or the youth could try to change the researchers' opinion on this matter.

Still another solution is for the youth to decide he or she is wrong and the researchers are right. Despite many years of belief in Christ as God, and many activities in support of that belief, he or she would change his or her opinion on the basis of a ten-minute communication. A key point emerges from the above analysis. The rational approach is rational only for the change agent. For the changee, change seems irrational. Should we change important beliefs each time someone thrusts disconfirming evidence on us? It is not surprising that "people are resistant to change."

The rational approach implies that the target of the change is irrational.

Figure 1: Use of Balance Theory for the Jesus Christ Study

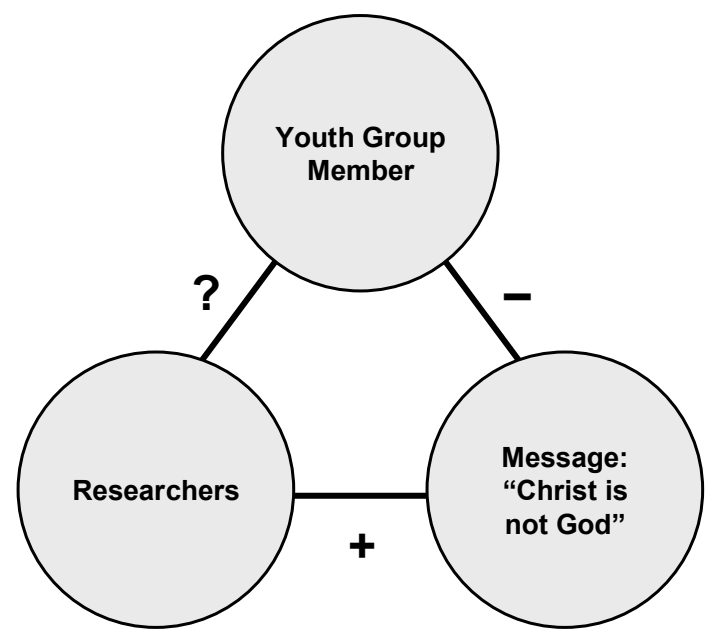

Balance theory can also be applied to the COMPU-HEART Case. The doctors' viewpoint differed from the staff s. It seemed rational for the doctors to try to change the staff s viewpoint or to decide they did not like the staff. These reactions showed up clearly in the role playing.

\section{THE DELTA TECHNIQUE}

The Delta Technique (named for the Greek letter commonly used to represent a small change) is my name for the following synthesis of previously published research.

The Delta Technique draws on the three phases of the change process described by Lewin (1952). These are analogous to the phases involved in changing the shape of a piece of ice: unfreezing, changing, and refreezing. Rather than going directly to the change, Lewin stressed the need to devote time and energy first to helping the client to unfreeze. In view of its importance, the unfreezing phase is discussed here in some detail. 


\section{Unfreezing}

The unfreezing phase is critical, yet often ignored. It creates stress to examine one's current beliefs. This stress frequently leads to the complaint: "We're wasting time. Let's get on with the change." But without the unfreezing phase, change efforts are likely to conflict with existing behavior. Referring back to the analogy, ice will shatter if enough pressure is applied to change its shape without going through the unfreezing phase.

Unfreezing can begin if a person is willing to tolerate the suspicion that his or her current procedure is not optimal. He or she then must search for disconfirming evidence (negative feedback). This is easier said than done; people generally seek evidence to support rather than disconfirm their beliefs.

The tendency for intelligent adults to avoid disconfirming evidence was demonstrated by Wason (1968). He provided three numbers" $2-4-6$ " to subjects, and they were asked to determine what rule had been used to generate the numbers. To gain information, the subjects were allowed to generate other series of three numbers to see if each new series was in agreement with the rule. The typical subject thought of a rule and then generated series that were co-w-tent with his or her rule. For example, if he or she thought the rule was "add 2 to each number," the series 6- $8-10$ could provide confirming evidence to him or her. It was unusual for a subject to use a series that was inconsistent with his or her own rule(e.g., the series 5-6-7 would violate the rule "add 2 to each number"). In short, the subject avoided evidence that might disconfirm his or her belief.

Subjects who were told that their rules were incorrect in Wason's study were allowed to generate additional series of numbers. The majority of these subjects kept the same rule that they had used previously, but they stated it in different words. Many people cling to their hypotheses even when given clear evidence that they are wrong.

The avoidance of negative feedback seems as common among scientists as among lay people, despite the fact that scientists receive formal education on the use of disconfirming evidence. Mahoney and DeMonbreun (1977) found that physical scientists and psychologists did no better than Protestant ministers on the 2-4-6 problem. Overall, only $13 \%$ of these subjects' trials sought disconfirming evidence.

When disconfirming evidence is thrust on people, they may use it irrationally as did the youth group members in the Jesus Christ study: The believers increased their belief in God. Or people may remember incorrectly: Fischhoff and Beyth (1975) found that subjects remembered their predictions differently when the eventual outcome was in conflict with their prediction. Or they may get mad: Janis and Mann (1965) found that smokers were annoyed when people told them about evidence on the dangers of smoking, Most likely, however, they will ignore the information: Dawes (1979) provides a perfectly rational argument in support of some simple quantitative decision models, but the models were not used despite the overwhelming evidence that they would improve on the current decision process.

The Delta Technique addresses the unfreezing phase by encouraging the client actively to seek disconfirming evidence. The client should suggest alternatives to his or her current procedure and then define what information would lead to an adoption of one of the alternatives.

Clients sometimes have difficulty in defining what information would disconfirm the current procedures. If this occurs, the change agent can present the client with a series of possible research outcomes and ask what decision would be made given each possibility. Would the new evidence affect decision making?

\section{Changing}

The change agent should assist the client in developing a low-risk approach to change. The client should maintain control over the change process while the change agent should provide support.

\section{Refreezing}

Once the change is accomplished, it is important to obtain periodic feedback on the change. If the change is a desirable one, it helps to restructure the organization to ensure that the new behavior is rewarded. 


\section{APPLYING THE DELTA TECHNIQUE}

This section outlines how you can apply the Delta Technique in a step-by-step fashion. Throughout this procedure, your role as a change agent is not to be the source of change, but to be a supporting actor in the client's change efforts.

As change agent, you first work with the clients to define the problem. Ask them how they perceive the problem and ask them to state the problem in different ways. (This helps to keep open alternative solutions because a problem statement often implies a solution.) Review what you heard with the clients, to be sure that you have heard them correctly. Such a summary also helps clients to clarify their own viewpoints. Include your own opinions on the problem after this.

Your clients include the people who are paying you. But clients also include other groups that are affected by the change. These "stakeholders" should be asked for their perspectives on the problem.

Given the problem statements, the change agent can help find alterative solutions. Once again, the clients are a major source of ideas. Clients may choose to maintain the current solution, but they should also experiment with at least one other feasible solution, even though this alternative can (and most likely will) appear to be inferior. In COMPU-HEART, the alternative involved the use of paramedics and computers, approaches that did not appeal to the doctors.

This use of alternative solutions, although often recommended, seems to be widely ignored. Even studies that are thought to represent the best in management science ignore this: Only $22 \%$ of the articles in the journal Management Science consider reasonable alternatives (Armstrong, 1979). By generating alternative solutions, management can change its role from "defender of the current solution" to "evaluator of future solutions." Instead of disconfirming the current solution, evidence can confirm another of management's alternatives. This is the second step of the Delta Technique and it completes the unfreezing phase.

Those affected must control each of the alternatives considered. To provide control, a three-step procedure is recommended: Experimentation, participation, and feedback.

\section{Experimentation}

Sell an experiment, not a change. The experiment should make sense to the people involved. It should provide a rational way to assess each of the possible solutions (e.g., it should allow for a comparison of alternatives to the current approach). The change agent provides expertise on experimental design and handles administrative details. An experiment can reduce risk by reducing the scope of the change and by putting a time limit on the change.

As the change agent, you should try to get the experiment started. Do this by asking for a commitment to act, however, small. That is, get your "foot in the door." The foot-in-the-door technique suggests that you ask initially for a small commitment. Preferably this commitment should be operational, it should be written, and it should have a time deadline. (For more on foot-in-the-door research, see Snyder and Cunningham, 1975.) In COMPU-HEART, users of the Delta Technique could ask the doctors to experiment with COMPU-HEART. To keep a foot in the door, a typical commitment was to "have a meeting next Tuesday to discuss the details of an experiment."

\section{Participation}

Encourage the stakeholders to participate in the design of the experiment (to the extent they desire). The clients should define the evidence that they would accept as sufficient to adopt an alternative solution. This may lead to suggestions on the experimental design. If the clients are not able to describe their change criteria, but are interested in the project, you can create some numbers and present "possible outcomes" of the project. The clients can then discuss how each outcome would affect their decisions. 
The doctors who went through the Delta Technique in the COMPU-HEART case often were able to outline what type of experiment would lead to change. These "experiments" varied greatly from one group to another.

Evidence on the value of participation has been provided in studies since the 1930s. A review of research to the mid-1960s is provided in Blumberg (1968). The findings were almost always the same: When employees were given control over the situation, they were often willing to make changes. Once the decision to change was made, implementation was rapid and successful. This contrasts with the long delays involved in traditional change processes.

Numerous additional studies have been published since Blumberg's review. They also show that participation helps in many situations. Lawler and Hackman (1969) demonstrated the value of participation in the adoption of a new incentive pay plan among building cleaners. French, Kay, and Meyer (1966) found that participation in goal setting by a subordinate manager increased the likelihood of successful changes by that manager. Bass (1977), using over 1400 managers from 12 countries in a simulated production task, found that teams that developed their own plans were more successful and more satisfied than those who were using an assigned plan.

\section{Feedback}

Enable those involved to monitor the results of the experiment. Fixed checkpoints should be established so that clients can terminate the experiment if they desire. Control over the change process implies that those involved have the right not to change.

The feedback should summarize the success or failure for each alternative over a number of trials. In general, avoid case-by-case feedback because few people use such data in a rational way (Ward and Jenkins, 1965). 1nstead, wait until a series of events has been generated and then present a summary so users can understand the relationships. Positive feedback at this stage helps to refreeze the change.

Role-playing subjects using the Delta Technique proposed that the COMPU-HEART program would be summarized to show success rates by treatment. These summaries would be presented to the doctors on a regular schedule. (The value of actually providing the feedback was not assessed in the COMPU-HEART study.)

Research has demonstrated the value of feedback, especially when the people involved have control over this feedback (see review by Ilgen, Fisher, \& Taylor, 1979). In n recent study, Becker (1978) showed that feedback was important in getting people to reduce their residential energy consumption.

\section{When Delta Should Not Be Applied}

The Delta Technique is not relevant for all situations. It does not seem to be as important for new employees, in short-term tasks (White, Mitchell, \& Bell, 1977), or in other situations in which group norms have not been established (Hillery \& Wexley, 1974). It is not useful if disagreement exists on the statement of the problem, a situation that is probably common in organizations.

One benefit of the Delta Technique is that it helps to avoid efforts that will not contribute to change. Beware of clients who say only, "We are open to change and would like you to obtain more information." If you cannot agree on the problem or if you cannot obtain commitment on what information could possibly be disconfirming to the present solution, it is best not to do the study. Certainly, many aspects of our lives (or the lives of our organizations) are not open to change. Do not spend time and money to collect information on these areas. If you ignore this advice, do not be surprised when you find that the study produces no change. Slovic and Fischhoff (1977) found that outcomes of research studies seldom surprised subjects, no matter what the reported results. Disconfirming evidence is most useful when the client is committed to finding such evidence.

\section{THE DELTA TECHNIQUE AND YOU}

The Delta Technique contradicts common sense. It is contrary to the years of experience during which we learned that, as change agents, we should use rational arguments and tell others how to change. We interpret our 
own actions as the source of change in others. This phenomena was demonstrated by Strickland (1958). Subjects in his experiments were asked to act as managers for two workers whom I will call Stan and Ned. The experiment was designed so the manager could easily communicate with Stan. In contrast, communication was not possible with Ned. Actually, Stan's and Ned's work followed a fixed pattern that had no relation to their manager. Furthermore, they each produced the same amount and quality of work. Whom did the manager trust?

He trusted Ned. He thought Stan required constant supervision and encouragement from him to produce the same output.

The illusion that we control others is not restricted to managers in business. It applies in roles such as being a government bureaucrat, a parent, an athletic coach, or a teacher. For research on the illusion of control, see Langer (1975). Mark Twain said it well in describing a fight

Thrusting my nose firmly between his teeth, I threw him heavily to the ground on top of me.

Before trying the Delta Technique on others, it seems fitting that you use it on yourself. To do this, first find some disagreement between the Delta Technique and your beliefs. Then suspend evaluation and answer the following question "What information could possibly convince me that this aspect of the Delta Technique is superior to my current behavior?" It helps to be specific and to write your answer to this question. (This is alternative $\mathrm{D}$ from the introduction.)

If you cannot find any ideas with which to disagree, or if you find an idea with which to disagree, but no information will change your mind, this article may be of little value. If you find an idea with which to disagree and can identify what information will change your mind, you must then decide how to obtain the information. To make sure you do this use the foot-in-the-door technique on yourself. First, find an idea from the Delta Technique. Then select a small step to get started. Set a time deadline for the completion of this step. Write:

- a description of the idea,

- the situation in which you will use it, and

- your time deadline.

(Based on responses from previous readers, you can make more effective use of this article if you invest at least five minutes now to write a "foot-in-the-door" plan.)

\section{EVIDENCE ON THE DELTA TECHNIQUE}

Studies on the various components of the Delta Technique have spanned half a century, although much of this research is recent. Note that over half of the studies cited in this article were published after 1970. The studies provide strong support for the Delta Technique. (The term "Delta Technique" was not used in these studies; it refers to my summary of the change strategy.) Whether this section of the article is relevant to you depends not on the evidence cited here, but on the evidence for which you are looking. Three important and recent studies are briefly summarized here.

(1) Lonnstedt (1975) examined 107 operations research projects in twelve Swedish companies. He conducted personal interviews with the head of each of the operations research departments and telephone interviews with users. When the clients participated in the problem definition, the likelihood of implementation of the change increased from $38 \%$ with no client participation to $82 \%$ with client participation.

(2) Zand and Sorensen (1975) examined change projects in industry by use of a mail survey completed by 154 management scientists. In the successful projects, the clients were in control during the 
"unfreezing, moving [change], and refreezing" phases of change. This seldom occurred for the unsuccessful projects.

(3) In a study of the implementation of 29 computer systems, Ginzberg (1979) examined the use of the Lewin change process. User perception of success was greater when the unfreezing, change, and refreezing phases were carried out successfully.

As noted at the beginning of this article, the most important way for you to gain evidence is to run your own experiment. The study by Nisbett and Borgida (1975) implied that personally generated evidence is more important to people than is evidence from studies done on others. This article allows the reader to replicate the COMPU-HEART role-playing case. Furthermore, the cited literature on change, with controlled studies, is easily available. In some cases, the change might not turn out as the change agent hoped: Those involved may prefer a "lower-quality solution." Of course, it is not just the quality of the solution that determines its overall effectiveness; acceptance is also important. A lower-quality decision that is accepted is often preferable to a higher quality decision that meets resistance. The Delta Technique is aimed at improving overall effectiveness.

A major disadvantage of the Delta Technique is that management may feel that its power is eroding. If the managers give up control now, they feel they will have less influence in the future. Some people have argued the opposite, claiming that the mutual sphere of influence grows when we allow others to influence us. In any event, the loss of control represents a concern for some managers.

\section{USE OF AN EXPERIENTIAL ARTICLE}

The format of this article departs from tradition in order to give the reader an opportunity to use elements of the Delta Technique. How did you react? Did you... (choose closest response):

(A) disagree with the Delta Technique?

(B) decide that a communication problem exists?

(C) feel that you read an exciting article?

(D) make a promise to experiment with the Delta Technique?

For those readers selecting A, B, or C, I hope that this article has at least created dissonance. Some readers, I hope, selected alternative D. Self-administered questionnaires were administered to nineteen Wharton MBA students who had read an earlier draft of this article: $32 \%$ selected D (experiment), $47 \%$ selected C (exciting article), $21 \%$ selected B (communication problem), and none selected A (disagreed with Delta).

\section{CONCLUSIONS}

An attitude survey and a role-playing experiment provided results consistent with naïve empiricism: namely, the typical approach to change is the rational approach. The rational approach is rational only from the change agent's viewpoint. It provides an outside force on the target with the implication that the target has been acting irrationally. Thus, this approach is irrational from the changee's viewpoint.

The Delta Technique removes the outside forces that are thrust on the client. The steps in the Delta Technique (illustrated in Figure 2) can help the client to go through the unfreezing, changing, and refreezing phases. The client should have control over each step.

The Delta Technique can help to identify feasible change projects and implement useful changes. It is appropriate for situations in which management sees a problem, but in which the desired change conflicts with their current beliefs. It is not needed in areas in which the change is consistent with the organization's perceptions of its mission. 
Evidence of the value of the Delta Technique was drawn from prior research and was supported by a roleplaying experiment that can be easily replicated.

\section{APPENDIX: INSTRUCTIONS FOR CHANGE AGENTS}

Assume that you had previous meetings with the doctors and that the problem you discussed (e.g., shortage of space in this exercise) was one that they view as a problem. Also assume that the solution, to use COMPUHEART, was one that had been raised as a possibility in those previous meetings. The first thing you do is to summarize the results of those previous meetings. This is crucial. You are here to assist them with their problem and to examine a possibility that they had asked you to look at.

I. PROBLEM DEFINITION:

Include all key stakeholders

Obtain alternative statements of the problem

Add your perspective as the change agent

II. ALTERNATIVE SOLUTIONS:

Include all key stakeholders

Develop list of reasonable alternatives

Identify disconfirming evidence (e.g. assess reactions to possible new evidence)

III. EXPERIMENTATION (WITH PARTICIPATION)

Use foot-in-door

Reduce risk

Work towards a rational design

Clients set criteria and constraints

Clients influence design

IV. FEEDBACK

Establish a schedule for feedback

Provide summary data

\section{Figure 2: Checklist for the Delta Technique}

To address the change itself, the following guidelines should be used:

(1) "Don't sell the change, sell an experiment."

Recognize that it is important to see how things will work in the particular situation. The experiment should allow the new method to be compared with the current method.

(2) Allow the managers to participate in the experiment.

Put yourself in a position of being there to provide a service to the managers. If they want you to carry out the experiment that's okay, but they will need to say how the decision will be made.

Therefore, you must:

a) Get them to specify the criteria (i.e., what will represent a success or a failure for a new method?). 
b) Let them make suggestions about how the experiment should be conducted (e.g., What types of changes would they like to see examined?).

The key question is what information do they regard as sufficient before they make the change.

\section{(3) Promise feedback.}

Let them know that they will be kept up to date on the experimental outcomes. This would allow them to terminate the experiment at any time.

Successful completion of this meeting will be in terms not of a promise to change, but rather of a specific promise to take the next small step (the "foot in the door"). For example, you could work "to schedule a meeting with top management to discuss the details for an experiment." 


\section{REFERENCES}

Armstrong, J. S . (1979), “Advocacy and objectivity in science,” Management Science, 25, 423-428.

Bass, B. M. (1977), "Utility of managerial self-planning in a simulated production task with replications in twelve countries," Journal of Applied Psychology, 62, 606-609.

Batson, C. D. (1976), "Rational processing or rationalization? The effect of disconfirming information on a stated religious belief," Journal of Personality and Social Psychology, 32, 176-184.

Becker, L. J. (1978), "Joint effect of feedback and goal setting on performance: A field study of residential energy conservation," Journal of Applied Psychology, 63, 428-433.

Blumberg, P. (1968), Industrial Democracy: The Sociology of Participation. New York: Schocken.

Brown, R. (1965), Social Psychology. New York: Free Press.

Dawes, R. M. (1979), “The robust beauty of improper linear models in decision making," American Psychologist, $34,571-582$.

Fischhoff, B., \& Beyth, R. (1975), "I knew it would happen: Remembered probabilities of once-future things," Organizational Behavior and Human Performance, 16.

French, J.R.P., Kay, E., \& Meyer, H. H. (1966), “Participation and the appraisal system,” Human Relations, 19, 320.

Ginzberg, M. J. (1979), “A study of the implementation process,” in Robert H. Doktor, R. L. Schultz, and D. P. Slevin (Eds.), The Implementation of Management Science. New York: North-Holland.

Hillery, J. M., \& Wexley, K. N. (1974), "Participation effects in appraisal interviews conducted in a training situation," Journal of Applied Psychology, 9, 168-171.

Ilgen, D. R., Fisher, C. D., \& Taylor, M. S. (1979), "Consequences of individual feedback on behavior in organizations," Journal of Applied Psychology, 64, 349-371.

Janis, I. L., A Mann, L. (1965), "Effectiveness of emotional role playing in modifying smoking habits and attitudes," Journal of Experimental Research in Personality, 1, 84-90.

Langer, E. S. (1975), “The illusion of control,” Journal of Personality and Social Psychology, 32, 311-328.

Lawler, E. E., \& Hackman, J. R. (1969), "The impact of employee participation in the development of pay incentive plans," Journal of Applied Psychology, 53, 467-471.

Lewin, K. (1952), “Group decision and social change,” in G. E. Swanson et al. (Eds.), Readings in Social Psychology. New York: Holt, Rinehart \& Winston.

Lonnstedt, L. (19750, "Factors related to the implementation of operations research solutions," Interfaces, 5, 23-30.

Marrow, A. J., \& French, J.R.P. (1945), “Changing a stereotype in industry,” Journal of Social Issues, 1, 33-37.

Mahoney, M. J., \& DeMonbreun, B. G. (1977), "Psychology of the scientist: An analysis of problem-solving bias," Cognitive Therapy and Research, 1, 229-238.

Mosteller, F. (1981), “Innovation and evaluation,” Science, 211, 881-886. 
Nisbett, R. E., \& Borgida, E. (1975), “Attribution and the psychology of prediction,” Journal of Personality and Social Psychology, 932-943.

Slovic P., \& Fischhoff, B. (1977), “On the psychology of experimental surprises,” Journal of Experimental Psychology: Human Perception and Performance, 544-551.

Snyder, M. \& Cunningham, M. R. (1975), "To comply or not to comply: Testing the self perception explanation of the 'foot-in-the-door' phenomenon," Journal of Personality and Social Psychology, 31, 64-67.

Strickland, L. H. (1958), “Surveillance and trust,” Journal of Personality, 26, 200-215.

Ward, W. C., \& Jenkins, H. M. (1965), "The display of information and the judgment of contingency," Canadian Journal of Psychology, 19, 231-241.

Wason, P. C. (1968), "On the failure to eliminate hypotheses - a second look," in P. C. Wason and P. N. JohnsonLaird (Eds.), Thinking and Reasoning. Baltimore: Penguin.

White, S. E., Mitchell, T. R., \& Bell, C. H., Jr. (1977), "Goal setting, evaluation apprehension, and social cues as determinants of job performance and job satisfaction in a simulated organization," Journal of Applied Psychology, 62, 665-673.

Zand, D. E., \& Sorensen, R. E. (1975), "Theory of change and the effective use of management science," Administrative Science Quarterly, 20, 532-545. 